\title{
Antibodies to extractable nuclear antigens (ENAS) in systemic lupus erythematosus patients: correlations with clinical manifestations and disease activity
}

\author{
Y. Emad', T. Gheita1', H. Darweesh', P. Klooster², R. Gamal ${ }^{3}$, H. Fathi', \\ N. El-Shaarawy ${ }^{5}$, M. Gamil ${ }^{6}$, M. Hawass ${ }^{7}$, R.M. El-Refai ${ }^{1}$, \\ H. Al-Hanafi, S. Abd-Ellatif ${ }^{8}$, A. Ismail ${ }^{10}$, J. Rasker ${ }^{2}$ \\ ${ }^{1}$ Rhumatology Department, Faculty of Medicine, Cairo University Cairo, Egypt; ${ }^{2}$ Faculty of Behavioral, \\ Management and Social sciences, Department Psychology, Health and Technology, University of Twente, \\ Enschede, The Netherlands; ${ }^{3}$ Rheumatology and rehabilitation Department, Faculty of Medicine, \\ Assiut University, Assiut, Egypt; ${ }^{4}$ Rheumatology Department, Faculty of Medicine, Fayoum University, \\ Fayoum, Egypt; ${ }^{5}$ Rheumatology and Rehabilitation Department, Suez Canal University, Ismailia, Egypt; \\ 6/nternal Medicine Department, Faculty of Medicine, Cairo University, Cairo, Egypt; ${ }^{7}$ Nephrology Department, \\ Al-Shorta Hospital, Cairo, Egypt; ${ }^{8} \mathrm{Clinical}$ and chemical pathology department Faculty of Medicine, \\ Cairo University, Cairo, Egypt; ${ }^{9}$ Department of Rheumatology and Rehabilitation at Al-Azhar University, \\ Cairo, Egypt; ${ }^{10}$ Dermatology department, Al-Azhar University, Cairo, Egypt
}

\begin{abstract}
The aim was to explore possible correlations of antibodies to extractable nuclear antigens (ENA) with clinical manifestations and disease activity indices in systemic lupus erythematosus (SLE) patients. A total of 70 consecutive SLE patients (64 females) were included. Disease activity was assessed by SLE activity index (SLEDAI), and British Isles Lupus Assessment Group (BILAG).

Anti-Ro/SSA correlated positively with, headache $(r=0.24, p=0.04)$, blurring of vision $(r=0.25, p=0.03)$ and SLEDAI $(r=0.25, p=0.04)$ and negatively with C3 $(r=-0.35, p=0.003)$. Anti-Ro/SSA correlated with anti La/SSB antibodies $(\mathrm{r}=0.69, \mathrm{p}<0.001)$, but not with anti-DNA, anti-RNP and anti-Sm antibodies. Anti-La/SSB antibodies correlated with headache $(r=0.26, p=0.03), \operatorname{SLEDAI}(r=0.25, \mathrm{p}=0.03)$ and negatively with $\mathrm{C} 3(\mathrm{r}=-0.34, \mathrm{p}=0.004)$. Anti-La/SSB did not correlate with anti-RNP or anti-Sm antibodies. Anti-Sm antibodies correlated with disease duration $(\mathrm{r}=0.34, \mathrm{p}=0.003), 24$ hours urinary proteins $(\mathrm{r}=0.31, \mathrm{p}=0.008)$, SLEDAI $(\mathrm{r}=0.31, \mathrm{p}=0.009)$, BILAG renal score $(r=0.29, p=0.02)$ and negatively with age at onset $(r=-0.27, p=0.02)$, WBCs $(r=-0.29, p=0.014)$ and $\mathrm{C} 4(\mathrm{r}=-0.25, \mathrm{p}=0.049)$. In multivariate analyses, anti-Ro/SSA antibodies remained associated with headache, blurring of vision and $\mathrm{C} 3$ and anti-La/SSB antibodies remained associated with $\mathrm{C} 3$ and with headache. Anti-Sm antibodies were independently associated with disease duration and total SLEDAI scores, while anti-RNP antibodies remained significantly associated with BILAG mucocutaneous scores only.

Antibodies to ENAs are associated with clinical aspects of SLE and may play a role in the assessment of disease activity. Insight into these ENAs may lead to new approaches to diagnostic testing, accurate evaluation of disease activity and lead to target approach for SLE.
\end{abstract}

Key words: Extractable nuclear antigens (ENA); Systemic lupus erythematosus (SLE); Disease activity; SLEDAI; BILAG.

\section{INTRODUCTION}

ystemic lupus erythematosus (SLE) is an autoimmune disease that is virtually always accompanied by the production of autoantibodies. In fact, it has been demonstrated that autoantibodies contribute directly to the pathologic changes of SLE. Since autoantibodies are central to the pathogenesis of the disorder, their development must coincide with or precede clinical disease (1). Antibodies to double-stranded DNA (dsDNA) are most closely associated with the clinical manifestations of the condition and appear to have a direct role in pathogenesis. On the contrary, the relationship
Corresponding author: Yasser Emad Professor of Rheumatology, Faculty of Medicine Cairo University, Egypt E-mail: yasseremad68@gmail.com 
between disease activity in SLE and antiextractable nuclear antigen (ENA) antibodies has not been well demonstrated (2). The high frequency of longitudinal fluctuation in anti-ENA antibodies suggests that a periodic reappraisal may be appropriate in seronegative patients with a suspect diagnosis of SLE (3).

A high number of antinuclear antibody (ANA) specificities can be detected in SLE. Some of these are related to a distinct clinical subset of disease, independently of their frequency. Autoantibodies against ENA are typically present many years before the diagnosis of SLE (4). Furthermore, the appearance of autoantibodies in patients with SLE tends to follow a predictable course, with a progressive accumulation of specific autoantibodies before the onset of SLE, while patients are still asymptomatic (4).

Autoantibodies targeting ENAs are hallmarks in the diagnosis of systemic autoimmune rheumatic diseases such as SLE (5). The primary antigenic targets of anti-ENA antibodies include U1-ribonucleoproteins (RNP), Sm (Smith antigen), topoisomerase I, Jo-1, Ro (SS-A), and La (SS-B) (6). SLE rarely presents with a negative ANA. Antibodies to ENA are sometimes ordered despite a negative ANA and may contribute to the diagnosis of SLE or other forms of connective tissue disease (CTD) (7).

This study was designed to look for possible correlations of antibodies to ENA with clinical manifestations and disease activity indices in a cohort of SLE patients.

\section{PATIENTS AND METHODS}

A total of 70 SLE patients agreed to participate. All patients fulfilled the 2012 Systemic Lupus International Collaborating Clinics (SLICC) classification criteria for SLE (8). Clinical data obtained included full medical history, general examination, and cardiovascular, chest, abdominal, neurological and locomotor system examination.

The SLE disease activity index (SLEDAI) (9) and British Isles Lupus Assessment Group (BILAG) index (10) were used to assess disease activity among the patients.
The SLEDAI index consists of 24 variables covering nine organ systems (including some immunological tests) scored according to weights derived using multiple regression techniques. The BILAG index includes 86 items and assesses eight organbased systems (general, mucocutaneous, neurological, musculoskeletal, cardiorespiratory, vascular, renal and hematological). Each system is given a score ranging from A to E. The disease activity assessed by both indices was classified as mild (score 0 -10), moderate (score 11-20), severe (21$45)$ and very severe $(>45)(9,10)$.

Laboratory investigations obtained at time of inclusion were: complete blood picture, liver and kidney function tests, urine analysis, 24-hour urinary proteins, serum complement levels (C3 and C4) and ANA. Anti-dsDNA (ELISA) was performed using standard methods.

\section{Anti-extractable nuclear antigens (ENA) assay}

Autoantibodies to Smith (anti-Sm), ribonucleoproteins (anti-RNP), SSA/Ro (anti$\mathrm{Ro} / \mathrm{SSA}$ ), and SSB/La (anti-La/SSB) were assessed by using Alegria $^{\circledR}$ assay which features barcoded 8-well-microstrips, called Alegria $^{\circledR}$ Test Strips. The Alegria ${ }^{\circledR}$ Test Strip holds a complete set of reagents including enzyme conjugate, enzyme substrate, sample buffer and a test specific control. The determination is based on an indirect enzyme-linked immune reaction with the following steps: antibodies present in positive samples bind to the antigen coated on the surface of the two reaction wells forming an antibody antigen complex. After incubation, a first washing step removes unbound and unspecific bound molecules. Subsequently added enzyme conjugate binds to the immobilized antibody-antigen complex. After incubation, a second washing step removes unbound enzyme conjugate. Addition of enzyme substrate solution results in hydrolyzation and color development during incubation. The intensity of the blue color correlates with the concentration of the antibody-antigen-complex and can be measured photometrically at $650 \mathrm{~nm}$. The 
calculation range of this assay is $0-200 \mathrm{U} /$ $\mathrm{mL}$ (normal $<15 \mathrm{U} / \mathrm{mL}$, border line $15-25$ $\mathrm{U} / \mathrm{mL}$, elevated $>25 \mathrm{U} / \mathrm{mL}$ ).

\section{Statistical analysis}

Analysis of data was performed with the statistical package for the social sciences (SPSS) version 15. As disease duration and most continuous laboratory and disease activity scores were positively skewed, these values were log-transformed (after adding 1 to eliminate zero values) to normalize their distribution before statistical analysis. Univariate Pearson correlations were computed between ENAs and clinical variables and disease activity indices. Variables significantly $(\mathrm{p}<0.05)$ associated with the respective ENA antibody were entered as independent variables into four separate multivariate logistic regression analyses with backward deletion $(\mathrm{p}<0.05)$ to identify independent associations.

\section{Ethics}

The design of the study was approved by the ethics committee of the Faculty of Medicine, Cairo University, Cairo, Egypt. All patients gave informed written consent to be enrolled into the study according to the Declaration of Helsinki.

\section{RESULTS}

The study included 70 SLE patients with a mean age of $35.4 \pm 10.2$ years and disease duration of $48.7 \pm 40.1$ months. The F:M ratio was 10.7:1. Demographic features, clinical manifestations, laboratory investigations and disease activity scores are presented in Table I.

Correlations between antibodies against ENA (Ro/SSA, La/SSB, U1RNP and Sm) and various demographic features, clinical manifestations, laboratory investigations and disease activity scores are presented in Table II. Anti-Ro/SSA correlated positively with blurring of vision $(\mathrm{r}=0.26, \mathrm{p}=0.03)$ and total SLEDAI score $(\mathrm{r}=0.25, \mathrm{p}=0.04)$ and negatively with $\mathrm{C} 3(\mathrm{r}=-0.35, \mathrm{p}=0.003)$. Additionally, anti-Ro/SSA significantly correlated with anti-La/SSB antibodies $(\mathrm{r}=0.69$, $\mathrm{p}<0.001)$, but not with the anti-RNP and
Table I - Demographic features, clinical manifestations, laboratory investigations and disease activity scores in the SLE patients.

\begin{tabular}{|c|c|c|}
\hline & $\begin{array}{c}\text { Variable } \\
\text { mean } \pm \text { SD or } n(\%)\end{array}$ & $\begin{array}{l}\text { SLE patients } \\
\qquad(n=70)\end{array}$ \\
\hline \multicolumn{2}{|c|}{ Age (years) } & $35.37 \pm 10.24$ \\
\hline \multicolumn{2}{|c|}{ Age at onset (years) } & $31.43 \pm 10.52$ \\
\hline \multicolumn{2}{|c|}{ Disease duration (months) } & $48.74 \pm 40.15$ \\
\hline \multicolumn{2}{|c|}{ Sex M:F n (\%) } & $6: 64(8.6: 91.4)$ \\
\hline \multicolumn{2}{|c|}{ Headache } & $37(52.9)$ \\
\hline \multicolumn{2}{|c|}{ Nephritis } & $8(11.4)$ \\
\hline \multicolumn{2}{|c|}{ Arthritis } & $34(48.6)$ \\
\hline \multicolumn{2}{|c|}{ Myalgia } & $58(82.9)$ \\
\hline \multicolumn{3}{|c|}{ Laboratory investigations } \\
\hline \multicolumn{2}{|c|}{$\operatorname{ESR}\left(\mathrm{mm} / 1^{\text {st }} \mathrm{h}\right)$} & $49.41 \pm 28.61$ \\
\hline \multicolumn{2}{|c|}{$\mathrm{CRP}(\mathrm{mg} / \mathrm{dL})$} & $1.97 \pm 2.29$ \\
\hline \multicolumn{2}{|c|}{ Hemoglobin (g/dL) } & $11.51 \pm 1.43$ \\
\hline \multicolumn{2}{|c|}{ WBCs $\left(\times 10^{3} / \mathrm{mm}^{3}\right)$} & $5.67 \pm 2.67$ \\
\hline \multicolumn{2}{|c|}{ Platelets $\left(x 10^{3} / \mathrm{mm}^{3}\right)$} & $278.1 \pm 80.67$ \\
\hline \multicolumn{2}{|c|}{ C3 $(\mu \mathrm{g} / \mathrm{mL})$} & $0.59 \pm 0.46$ \\
\hline \multicolumn{2}{|c|}{$\mathrm{C} 4(\mu \mathrm{g} / \mathrm{mL})$} & $0.22 \pm 0.15$ \\
\hline \multicolumn{2}{|c|}{ Serum creatinine (mg/dL) } & $0.69 \pm 0.19$ \\
\hline \multicolumn{2}{|c|}{ Proteinuria (mg/24 hr) } & $207.59 \pm 271.74$ \\
\hline \multicolumn{2}{|c|}{ Anti-DNA titer } & $118.37 \pm 146.4$ \\
\hline \multicolumn{2}{|c|}{ Hemolytic anemia } & $17(24.3)$ \\
\hline \multicolumn{2}{|c|}{ ACL antibodies } & $13(18.6)$ \\
\hline \multicolumn{3}{|c|}{ ENA positivity } \\
\hline \multicolumn{2}{|c|}{ Anti-Ro (SS-A) } & $21(30)$ \\
\hline \multicolumn{2}{|c|}{ Anti-La (SS-B) } & $14(20)$ \\
\hline \multicolumn{2}{|c|}{ Anti-SM } & $19(27.1)$ \\
\hline \multicolumn{2}{|c|}{ Anti-RNP } & $7(10)$ \\
\hline \multicolumn{3}{|c|}{ Disease activity score } \\
\hline \multicolumn{2}{|c|}{ SLEDAI } & $14.23 \pm 9.38$ \\
\hline \multirow{7}{*}{ 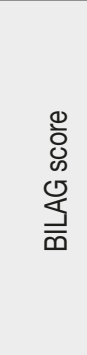 } & Musculoskeletal & $2.34 \pm 0.61$ \\
\hline & Renal & $0.77 \pm 1.16$ \\
\hline & Mucocutaneous & $1.80 \pm 0.65$ \\
\hline & CVS/respiratory & $0.19 \pm 0.46$ \\
\hline & Vasculitis & $0.47 \pm 0.79$ \\
\hline & Haematological & $1.71 \pm 0.98$ \\
\hline & CNS & $0.49 \pm 1.07$ \\
\hline
\end{tabular}

SLE, systemic lupus erythematosus; Anti-DNA, anti-deoxyribonucleic acid; ACL, anti-cardiolipin; Anti-Sm, anti-Smith; anti-RNP, antiribonuclear protein; SLEDAI, systemic lupus erythematosus disease activity index; BILAG, British Isles Lupus Assessment Group; CVS, cardiovascular system; CNS, central nervous system. 
anti-Sm antibodies. The anti-La/SSB antibodies correlated positively with headache $(\mathrm{r}=0.26, \mathrm{p}=0.03)$, SLEDAI scores $(\mathrm{r}=0.26$, $\mathrm{p}=0.04)$, vasculitis BILAG score $(\mathrm{r}=0.25$, $\mathrm{p}=0.04)$ and negatively with $\mathrm{C} 3(\mathrm{r}=-0.34$, $\mathrm{p}=0.004)$. Moreover, anti-La/SSB showed no significant correlations with anti-RNP or anti-Sm antibodies. Regarding anti-Sm antibodies, a significant correlation was found with age at onset $(\mathrm{r}=-0.27, \mathrm{p}=0.02)$, disease duration $(\mathrm{r}=0.36, \mathrm{p}=0.003), 24$ hour urinary proteins $(\mathrm{r}=0.31, \mathrm{p}=0.008)$, and SLEDAI score $(r=0.31, p=0.009)$ and renal BILAG $(\mathrm{P}=0.29, \mathrm{P}=0.02)$. A negative

Table II - Correlation between extractable nuclear antigens and clinical features, laboratory findings and disease activity indices in SLE patients.

\begin{tabular}{|c|c|c|c|c|c|c|c|c|c|}
\hline \multirow{2}{*}{\multicolumn{2}{|c|}{$\begin{array}{c}\text { Variable } \\
r(p)\end{array}$}} & \multicolumn{8}{|c|}{ Anti-ENAs in SLE patients ( $n=70)$} \\
\hline & & \multicolumn{2}{|c|}{ Anti-Ro } & \multicolumn{2}{|c|}{ Anti-La } & \multicolumn{2}{|c|}{ Anti-Sm } & \multicolumn{2}{|c|}{ Anti-RNP } \\
\hline \multicolumn{2}{|c|}{ Age } & -0.11 & $(0.37)$ & -0.02 & $(0.88)$ & -0.16 & $(0.19)$ & -0.09 & $(0.45)$ \\
\hline \multicolumn{2}{|c|}{ Age at onset } & -0.17 & $(0.15)$ & -0.07 & $(0.57)$ & -0.27 & $(0.02)^{*}$ & -0.13 & $(0.28)$ \\
\hline \multicolumn{2}{|c|}{ Disease duration } & 0.19 & $(0.12)$ & 0.15 & $(0.23)$ & 0.36 & $(0.003)^{*}$ & 0.14 & $(0.25)$ \\
\hline \multicolumn{2}{|c|}{ Headache } & 0.24 & $(0.04)^{*}$ & 0.26 & $(0.03)^{*}$ & -0.003 & $(0.98)$ & -0.07 & (0.58) \\
\hline \multicolumn{2}{|c|}{ Blurring of vision } & 0.26 & $(0.03)^{\star}$ & 0.16 & $(0.19)$ & 0.08 & $(0.49)$ & -0.12 & $(0.32)$ \\
\hline \multicolumn{2}{|c|}{ Nephritis } & 0.16 & $(0.2)$ & 0.16 & $(0.19)$ & 0.29 & $(0.02)^{*}$ & 0.18 & (0.14) \\
\hline \multicolumn{2}{|c|}{ Arthritis } & 0.05 & (0.68) & 0.09 & $(0.48)$ & -0.14 & $(0.24)$ & -0.04 & $(0.75)$ \\
\hline \multicolumn{2}{|c|}{ Myalgia } & 0.13 & $(0.28)$ & 0.13 & $(0.27)$ & 0.02 & $(0.86)$ & 0.03 & $(0.84)$ \\
\hline \multicolumn{2}{|c|}{ ESR } & -0.04 & $(0.70)$ & -0.05 & $(0.7)$ & 0.14 & $(0.25)$ & 0.17 & $(0.15)$ \\
\hline \multicolumn{2}{|c|}{ CRP } & 0.09 & (0.48) & 0.12 & $(0.33)$ & 0.1 & $(0.43)$ & 0.14 & $(0.26)$ \\
\hline \multicolumn{2}{|c|}{ Hemoglobin } & -0.07 & $(0.57)$ & -0.02 & $(0.87)$ & 0.13 & $(0.3)$ & 0.04 & $(0.73)$ \\
\hline \multicolumn{2}{|c|}{ WBCs } & -0.03 & $(0.79)$ & -0.11 & $(0.35)$ & -0.29 & $(0.014)^{\star}$ & -0.25 & $(0.04)^{*}$ \\
\hline \multicolumn{2}{|c|}{ Platelets } & -0.11 & $(0.37)$ & -0.16 & $(0.19)$ & -0.16 & $(0.18)$ & 0.02 & $(0.87)$ \\
\hline \multicolumn{2}{|l|}{$\mathrm{C} 3$} & -0.35 & $(0.003)^{\star \star}$ & -0.34 & $(0.004)^{\star *}$ & -0.11 & $(0.39)$ & -0.17 & $(0.16)$ \\
\hline \multicolumn{2}{|l|}{$\mathrm{C} 4$} & -0.19 & $(0.12)$ & -0.2 & $(0.09)$ & -0.24 & $(0.049)^{*}$ & -0.25 & $(0.04)^{*}$ \\
\hline \multicolumn{2}{|c|}{ Serum creatinine } & -0.1 & $(0.42)$ & -0.02 & $(0.89)$ & 0.01 & $(0.93)$ & 0.02 & $(0.85)$ \\
\hline \multicolumn{2}{|c|}{$24 \mathrm{~h}$ proteinuria } & 0.12 & $(0.31)$ & 0.17 & $(0.15)$ & 0.31 & $(0.008)^{*}$ & 0.15 & $(0.22)$ \\
\hline \multicolumn{2}{|c|}{ Hemolytic anemia } & 0.07 & $(0.59)$ & 0.05 & $(0.68)$ & 0.18 & $(0.14)$ & -0.08 & $(0.52)$ \\
\hline \multicolumn{2}{|c|}{ Anti-DNA titer } & 0.01 & $(0.91)$ & 0.07 & $(0.54)$ & 0.27 & $(0.02)$ & 0.31 & $(0.009)^{*}$ \\
\hline \multicolumn{2}{|c|}{ ACL syndrome } & 0.008 & $(0.95)$ & 0.13 & $(0.29)$ & 0.12 & $(0.32)$ & -0.04 & $(0.76)$ \\
\hline \multicolumn{10}{|c|}{ Disease activity score } \\
\hline \multicolumn{2}{|c|}{ SLEDAI } & 0.25 & $(0.04)^{*}$ & 0.26 & $(0.03)^{*}$ & 0.31 & $(0.009)^{*}$ & 0.09 & $(0.44)$ \\
\hline \multirow{7}{*}{ 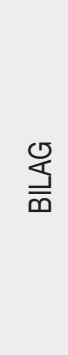 } & Musculoskeletal & 0.14 & $(0.24)$ & 0.19 & $(0.12)$ & -0.13 & $(0.27)$ & -0.19 & $(0.12)$ \\
\hline & Renal & 0.19 & $(0.13)$ & 0.22 & $(0.06)$ & 0.29 & $(0.02)^{\star}$ & -0.02 & $(0.89)$ \\
\hline & Mucocutaneous & -0.09 & $(0.48)$ & 0.1 & $(0.41)$ & -0.01 & $(0.94)$ & 0.25 & $(0.04)^{*}$ \\
\hline & CVS/respiratory & -0.06 & $(0.61)$ & 0.11 & $(0.37)$ & -0.11 & $(0.38)$ & -0.14 & $(0.26)$ \\
\hline & Vasculitis & 0.096 & $(0.42)$ & 0.25 & $(0.04)^{*}$ & 0.21 & $(0.09)$ & -0.02 & $(0.88)$ \\
\hline & Hematological & 0.1 & $(0.43)$ & 0.037 & $(0.76)$ & 0.21 & $(0.08)$ & 0.2 & $(0.1)$ \\
\hline & CNS & 0.14 & $(0.25)$ & 0.07 & $(0.54)$ & 0.05 & $(0.66)$ & -0.15 & $(0.21)$ \\
\hline
\end{tabular}

SLE, systemic lupus erythematosus; Anti-DNA, anti-deoxyribonucleic acid; ACL, anticardiolipin; SLEDAl, systemic lupus erythematosus disease activity index; BILAG, British Isles Lupus Assessment Group; Anti-Sm, anti-Smith; anti-RNP, antiribonuclear protein; CVS, cardiovascular system; CNS, central nervous system. *Significant at $p<0.05$. 
association was found with the white blood cells (WBCs) count $(\mathrm{r}=-0.29, \mathrm{p}=0.01)$, and $\mathrm{C} 4 \quad(\mathrm{r}=-0.24, \mathrm{p}=0.04)$. Finally, the anti-RNP antibodies correlated positively with the BILAG mucocutaneous score $(\mathrm{r}=0.25, \mathrm{p}=0.04)$ and negatively with the WBCs $(\mathrm{r}=-0.25, \mathrm{p}=0.04)$ and $\mathrm{C} 4(\mathrm{r}=-0.25$, $\mathrm{p}=0.04)$. The $\mathrm{C} 3$ was significantly reduced in patients with a positive anti-Ro and antiLa. The SLEDAI score was significantly higher in SLE patients with positive anti$\mathrm{La}$ and anti-Sm.

Lupus nephritis (LN) significantly correlated with anti-dsDNA titer $(r=0.37, p=0.002)$, positive anti-Sm antibodies $(r=0.29$, $\mathrm{p}=0.017$ ), while no significant correlations were observed with anti-Ro $(r=0.16, p=0.2)$, anti-La $(\mathrm{r}=0.16, \mathrm{p}=0.19)$ and anti-RNP $(\mathrm{r}=0.18, \mathrm{p}=0.14)$. Moreover, the SLEDAI score significantly correlated with anti-dsDNA titer $(\mathrm{r}=0.28, \mathrm{p}=0.01)$, anticardiolipin (aCL) antibodies ( $\mathrm{r}=0.47, \mathrm{p}<0.001)$, ESR $(\mathrm{r}=0.46, \mathrm{p}<0.001), \mathrm{CRP}(\mathrm{r}=0.5, \mathrm{p}<0.001)$, 24-hour urinary proteins $(\mathrm{r}=0.56, \mathrm{p}<0.001)$, nephritis $(\mathrm{r}=0.57, \mathrm{p}<0.001)$ and Coomb's test $(r=0.28, p<0.01)$, and negatively correlated with $\mathrm{C} 4(\mathrm{r}=-0.39, \mathrm{p}=0.001)$ and platelet count $(\mathrm{r}=-0.39, \mathrm{p}=0.001)$.

Furthermore, Anti-dsDNA titer showed positive correlations with the BILAG renal score $(\mathrm{r}=0.320, \mathrm{p}=0.007)$, SLEDAI score $(\mathrm{r}=0.280, \mathrm{p}=0.019), 24$-hour urinary proteins $(\mathrm{r}=0.285, \mathrm{p}=0.017)$, and ESR $(\mathrm{r}=0.268, \mathrm{p}=0.025)$. No other significant correlations were observed between antidsDNA and other BILAG scores for other major systems.

In multivariate analyses Anti-Ro/SSA antibodies remained associated with headache, blurring of vision and C3 and Anti-La/ SSB antibodies remained associated with C3 and with headache. Anti-Sm antibodies were independently associated with disease duration and total SLEDAI scores, while anti-RNP antibodies remained significantly associated with BILAG mucocutaneous scores only.

\section{DISCUSSION}

The current cross-sectional study was conducted to investigate ENA autoantibodies among a cohort of SLE patients and to examine possible associations with different disease manifestations as well as disease activity indices. Specifically in SLE, the appearance of ENA autoantibodies precedes the clinical onset of the disease, a finding that underscores their potential importance in the pathogenesis. ANA, anti-Ro, anti-La, and $\mathrm{aCL}$ antibodies appear first, followed by anti-ds DNA antibodies, and then by anti-Sm and anti-RNP antibodies (11-16). Furthermore, the appearance of autoantibodies in patients with SLE tends to follow a predictable course, with a progressive accumulation of specific autoantibodies before the onset of SLE, while patients are still asymptomatic (11).

It is noteworthy that anti-Ro, anti-La, aCL, and ANA are in fact relatively common in normal persons who never have clinical symptoms of an auto-immune rheumatic disease. In contrast, anti-dsDNA, anti-Sm, and anti-RNP antibodies are very rare in normal persons $(17,18)$.

Hoffman et al. described the presence of 5 clusters of autoantibodies (anti-Sm/RNP, anti-Ro/La, anti-ribosomal P, anti-histone, and anti-dsDNA antibodies) in the setting of SLE (19). Tapanes et al. reported that the presence of anti-Sm/ RNP or anti-Ro/ $\mathrm{La} / \mathrm{Sm} / \mathrm{RNP}$ was associated with a more benign form of lupus nephropathy (20). It was found that SLE patients with Sm/RNP antibodies had a lower prevalence of urine cellular casts (19) and represent a subset of lupus patients with less major organ involvement (21).

Antigen-antibody reactions involving the ENAs including Ro, RNP, and Sm may also contribute to the pathogenesis of $\mathrm{LN}$; however a definitive relationship has not been fully established (22). In our study, a significant correlation was observed between LN with anti-dsDNA titer and anti-Sm antibodies. These results can be explained by the fact that ANAs, with the ability to fix complement, are primarily immunoglobulin (Ig) G1 and G3, and these subclasses correlate with the presence of LN and levels of anti-dsDNA antibodies. Of the ENAs, anti-Ro, anti-La and U1 RNP antibodies are primarily $\operatorname{IgG1}$, whereas 
anti-Sm antibody contains equal amounts of IgG1 and IgG2 (23). In a recent study, anti-Sm identified at kidney biopsy was suggested to have a predictive value for the early poor outcome of biopsy-proven $\mathrm{LN}$ during the follow-up period (24).

An established association has been reported between anti-Sm antibody levels and the SLEDAI as well as between anti-U1-RNP antibodies and the occurrence of LN (25). In an Afro-Caribbean cohort of SLE patients, rash, alopecia, mouth ulcers, serositis, neurological, joint and renal involvement were significantly associated with the presence of anti-Sm and anti-RNP antibodies while joint involvement was associated with the presence of anti-Ro and anti-La antibodies (26). In our study we observed that anti-Ro was positive in $30 \%$, anti-La in $20 \%$, anti-Sm in $27.1 \%$ and anti-RNP in $10 \%$ of the cases. In a recent study that included a cohort of 552 SLE patients, antinuclear antibodies were detected in $99.8 \%$ of patients, followed by anti-ds DNA $(81.3 \%)$, anti-SSA/Ro $(58.7 \%)$, anti-RNP (36.8\%), anti-Sm (35.7\%), and anti-SSB/La (15\%) (27).

Among ANAs, anti-Sm and anti-RNP antibodies are of the utmost importance in clinical practice and the study of the mechanisms inducing their production has opened up new perspectives and helped to elucidate the pathogenesis of autoimmune disorders (28). The study of autoantibodies, their production and their role in the immunopathology of SLE is complex. Insight into these issues is not only of theoretical interest but may also lead to new approaches to diagnostic testing, accurate assessment of disease activity and more preventative or specific therapies (29).

The cross sectional design of the study forms a limitation as we cannot say whether the correlations will persist over time. For that reason, we did not study specifically relations with, for example, pregnancy and other detailed clinical manifestations. We encourage more in-depth analysis of the relation of ENAs to the detailed clinical manifestations, damage scores, pregnancy and outcome.

\section{CONCLUSIONS}

Antibodies to ENAs are associated with clinical aspects of SLE, seem to contribute to the pathogenesis of LN and play an important role in the assessment of disease activity. Insight into these ENAs may lead to new approaches to diagnostic testing, accurate evaluation of disease activity and lead to target approach for SLE. A larger scale longitudinal study is recommended in the future to confirm our findings and verify the core role of the ENAs in the prognosis and course of SLE disease.

Conflict of interest: none of the authors has any conflict of interest regarding this study.

\section{REFERENCES}

1. Reichlin M, Harley JB. Antibodies to Ro/ SSA and La/SSB. In: Wallace DJ, Hahn BH, eds. Dubois' lupus erythematosus. 6th ed. Philadelphia: Lippincott Williams \& Wilkins; 2002; 467-80.

2. Agarwal S, Harper J, Kiely PD. Concentration of antibodies to extractable nuclear antigens and disease activity in systemic lupus erythematosus. Lupus. 2009; 18: 407-12.

3. Faria AC, Barcellos KS, Andrade LE. Longitudinal fluctuation of antibodies to extractable nuclear antigens in systemic lupus erythematosus. J Rheumatol. 2005; 32: 1267-72.

4. Fredi M, Cavazzana I, Quinzanini M, et al. Rare autoantibodies to cellular antigens in systemic lupus erythematosus. Lupus.2014; 23: 672-75.

5. Mahler M, Fritzler MJ. Epitope specificity and significance in systemic autoimmune diseases. Ann N Y Acad Sci. 2010; 1183: 267-87.

6. Bentow C, Swart A, Wu J, et al. Clinical performance evaluation of a novel rapid response chemiluminescent immunoassay for the detection of autoantibodies to extractable nuclear antigens. ClinChim Acta. 2013; 424: 141-7.

7. Davis JM 3rd, Moder KG, Homburger HA, Ytterberg SR. Clinical features of 39 patients with antibodies to extractable nuclear antigens despite negative antinuclear antibodies: evidence for autoimmunity including neurologic and connective tissue diseases. Medicine (Baltimore). 2005; 84: 208-17.

8. Petri M, Orbai AM, Alarcón GS, et al. Derivation and validation of the Systemic Lupus International Collaborating Clinics classification criteria for SLE. Arthritis Rheum. 2012; 64: 2677-86. 
9. Bombardier C, Gladman D, Urowitz M, et al. Derivation of the SLEDAI. A disease activity index for lupus patients. The Committee on Prognosis Studies in SLE. Arthritis Rheum. 1992; 35: 630-40.

10. Hay EM, Bacon PA, Gordon C, et al. The BILAG index: a reliable and valid instrument for measuring clinical disease activity in systemic lupus erythematosus. Q J Med. 1993; 86: 447-58.

11. Arbuckle MR, McClain MT, Rubertone MV, et al. Development of autoantibodies before the clinical onset of systemic lupus erythematosus. N Engl J Med. 2003; 349: 1526-33.

12. Vlachoyiannopoulos PG, Tzavara V, Dafni $\mathrm{U}$, et al. Clinical features and evolution of antinuclear antibody positive individuals in a rheumatology outpatient clinic. J Rheumatol. 1998; 25: 886-91.

13. Mosca M, Tavoni A, Neri R, et al. Undifferentiated connective tissue diseases: the clinical and serological profiles of 91 patients followed for at least 1 year. Lupus. 1998; 7 : 95-100.

14. Press J, Uziel Y, Laxer R, et al. Long-term outcome of mothers of children with complete congenital heart block. Am J Med. 1996; 100: 328-32.

15. Julkunen H, Kurki P, Kaaja R, et al. Isolated congenital heart block: long-term outcome of mothers and characterization of the immune response to SS-A/Ro and SS-B/La. Arthritis Rheum. 1993; 36: 1588-98.

16. Satoh M, Yamagata H, Watanabe F, et al. Development of anti-Sm and anti-DNA antibodies followed by clinical manifestation of systemic lupus erythematosus in an elderly woman with long-standing Sjogren's syndrome. Lupus. 1995; 4: 63-5.

17. Gaither KK, Fox OF, Yamagata H, et al. Implications of anti-Ro/Sjögren's syndrome A antigen autoantibody in normal sera for autoimmunity. J Clin Invest. 1987; 79: 841-6.

18. Zarmbinksi MA, Messner RP, Mandel JS. Anti-dsDNA antibodies in laboratory workers handling blood from patients with systemic lupus erythematosus. J Rheumatol. 1992; 19: 1380-4.

19. Hoffman IE, Peene I, Meheus L, et al. Specific antinuclear antibodies are associated with clinical features in systemic lupus erythematosus. Ann Rheum Dis. 2004; 63: 1155-8.

20. Tapanes FJ, Vasquez M, Ramirez R, et al. Cluster analysis of antinuclear autoantibodies in the prognosis of SLE nephropathy: are anti-extractable nuclear antibodies protective? Lupus. 2000; 9: 437-44.

21. Ter Borg EJ, Groen H, Horst G, et al. Clinical associations of antiribonucleoprotein antibodies in patients with systemic lupus erythematosus. Semin Arthritis Rheum. 1990; 20:16473.

22. Alba P, Bento L, Cuadrado MJ, et al. AntidsDNA, anti-Sm antibodies, and the lupus anticoagulant: significant factors associated with lupus nephritis. Ann Rheum Dis. 2003; 62: 556-60.

23. Ravirajan CT, Rowse L, MacGowan JR, Isenberg DA. An analysis of clinical disease activity and nephritis-associated serum autoantibody profiles in patients with systemic lupus erythematosus: a cross-sectional study. Rheumatology (Oxford). 2001; 40: 1405-12.

24. Ahn SS, Yoo BW, Song JJ, et al. Anti-Sm is associated with the early poor outcome of lupus nephritis. Int J Rheum Dis. 2016; 19: 897-902.

25. Yamamoto AM, Amoura Z, Johannet C, et al. Quantitative radioligand assays using de novosynthesized recombinant autoantigens in connective tissue diseases: new tools to approach the pathogenic significance of anti-RNP antibodies in rheumatic diseases. Arthritis Rheum. 2000; 43: 689-98.

26. Morais SA, Isenberg DA. A study of the influence of ethnicity on serology and clinical features in lupus. Lupus. 2017; 26: 17-26.

27. Li WG, Ye ZZ, Yin ZH, Zhang K. Clinical and immunological characteristics in 552 systemic lupus erythematosus patients in a southern province of China. Int J Rheum Dis. 2017; 20: 68-75.

28. Migliorini P, Baldini C, Rocchi V, Bombardieri S. Anti-Sm and anti-RNP antibodies. Autoimmunity. 2005; 38: 47-54.

29. Ravirajan CT, Rowse L, MacGowan JR, Isenberg DA. An analysis of clinical disease activity and nephritis-associated serum autoantibody profiles in patients with systemic lupus erythematosus: a cross-sectional study. Rheumatology (Oxford). 2001; 40: 1405-12. 